\title{
Breathlessness and COVID-19: A Call for Research
}

\author{
Lisa Hentsch ${ }^{a}$ Sara Cocetta ${ }^{b}$ Gilles Allali ${ }^{\text {c, } d}$ Isabelle Santana ${ }^{e}$ \\ Rowena Eason ${ }^{f}$ Emily Adam $^{g}$ Jean-Paul Janssens ${ }^{\text {h }}$
}

aDivision of Palliative Medicine, Geneva University Hospitals, Geneva, Switzerland; 'blndependent Researcher, Udine, Italy; 'Division of Neurology, Geneva University Hospitals and Faculty of Medicine, University of Geneva, Geneva, Switzerland; 'Division of Cognitive and Motor Aging, Department of Neurology, Albert Einstein College of Medicine,

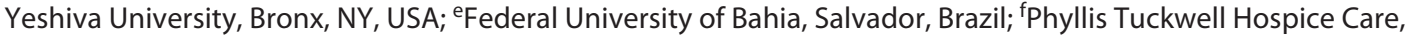
Surrey, UK; IIndependent Researcher, London, UK; ' $D i v i s i o n$ of Pulmonary Diseases, Geneva University Hospital, Geneva, Switzerland

\section{Keywords}

Coronavirus disease $19 \cdot$ Severe acute respiratory syndrome coronavirus 2 - Breathlessness - Dyspnoea - Neuroinvasion

\begin{abstract}
Breathlessness, also known as dyspnoea, is a debilitating and frequent symptom. Several reports have highlighted the lack of dyspnoea in a subgroup of patients suffering from COVID-19, sometimes referred to as "silent" or "happy hypoxaemia." Reports have also mentioned the absence of a clear relationship between the clinical severity of the disease and levels of breathlessness reported by patients. The cerebral complications of COVID-19 have been largely demonstrated with a high prevalence of an acute encephalopathy that could possibly affect the processing of afferent signals or top-down modulation of breathlessness signals. In this review, we aim to highlight the mechanisms involved in breathlessness and summarize the pathophysiology of COVID-19 and its known effects on the brain-lung interaction. We then offer hypotheses for the alteration of breathlessness perception in COVID-19 patients and suggest ways of further researching this phenomenon. @ $2021 \mathrm{~S}$. Karger AG, Basel
\end{abstract}

\section{Introduction}

Breathlessness, also known as dyspnoea, is a common and distressing symptom. It has been defined as a subjective experience of breathing discomfort, consisting of qualitatively distinct sensations that vary in intensity [1]. Many different conditions, such as lung disease, chronic heart failure, and neurodegenerative diseases, cause similar subjective sensations. It has therefore been hypothesized that there may be a common central nervous system pathway involved in the perception of dyspnoea, irrespective of the underlying cause [1].

At the end of 2019, a new respiratory infection, coronavirus disease 19 (COVID-19), caused by a novel coronavirus, the severe acute respiratory syndrome coronavirus 2 (SARS-CoV-2), was first reported in Wuhan, China. Although the prevalence of severe disease was high, the prevalence of dyspnoea in COVID-19 patients was relatively low, compared to other coronaviruses such as the severe acute respiratory syndrome (SARS)-CoV (SARS$\mathrm{CoV}$ ) or the Middle East respiratory syndrome (MERS)$\mathrm{CoV}$ (MERS-CoV) [2]. Levels of dyspnoea appear to vary significantly amongst patients suffering from COVID-19 
ranging from 18.6 to $59 \%[3,4]$. In a systematic review and meta-analysis, Rodriguez-Morales et al. [5] found an overall dyspnoea prevalence of 45.6\% (95\% CI: $10.9-$ $80.4 \%$ ). More recently, Li et al. [6] conducted a systematic review that included the data of 1,994 patients. The overall percentage of patients experiencing dyspnoea was $21.9 \%$. Some of the variation in dyspnoea prevalence within and between studies can be explained by differences in how it was investigated and documented. It may also be related to the setting. In a prospective study looking at the clinical course of hospitalized patients with COVID-19, Huang et al. [7] found a prevalence of breathlessness as high as $92 \%$ amongst patients hospitalized in intensive care units versus $37 \%$ in patients in non-intensive care units. Many of the studies included in systematic reviews are retrospective and reported symptoms on admission extracted retrospectively from patients' medical records $[8,9]$. How, when, and by whom dyspnoea was evaluated is unclear and will be discussed further.

Despite dyspnoea being significantly associated with a higher mortality in adults with COVID-19 (OR $=4.34$, 95\% CI: [2.68-7.05], $p<0.001, I^{2}=69.2 \%, p<0.001$, random-effects model) [10], it is not always correlated with the severity of the disease. Indeed, Guan et al. [3] found a level of dyspnoea as low as $18.6 \%$ in a retrospective data analysis of 1,099 patients, despite $86 \%$ having abnormal CT scans and low $\mathrm{PaO}_{2} / \mathrm{FiO}_{2}$ ratios. Other case studies have shown that the so-called "silent hypoxaemia" was observed even in patients with elevated $\mathrm{PaCO}_{2}$ which, combined with a low $\mathrm{PaO}_{2}$, should induce dyspnoea. Indeed, as will be discussed below, respiratory centres are extremely sensitive to increases in $\mathrm{CO}_{2}$, which will rapidly increase minute ventilation and generally cause respiratory discomfort [11]. This has been observed in patients with and without comorbidities [11].

Why certain patients present with "silent" or "happy hypoxaemia" is still unclear at this stage. Certain groups of patients, notably the elderly and patients suffering from diabetes, may be more at risk for reasons that will be discussed further. To this day, no patient characteristics or comorbidities have been clearly associated with an alteration in breathlessness perception in COVID-19. Li et al. [12] have suggested that the neuroinvasive potential of SARS-CoV-2 may be responsible for the variation in breathlessness perception due to its effect on the brainstem and the medullary cardiorespiratory centre of infected patients. Others have suggested that the lack of breathlessness is due to effects on the cortical rather than sub-cortical structures [13]. Diminished breathlessness perception could also be due to the alteration of periph-

Breathlessness and COVID-19: A Call for Research eral structures such as the altered perception of muscle effort, decreased thoracic compliance, or altered input from mechanoreceptors from the respiratory tract and chest wall [14]. It has also been hypothesized that by directly affecting the vagal nerve, SARS-CoV-2 impedes mechanical and chemical receptors on that nerve, generally responsible for the exacerbation of dyspnoea $[15,16]$.

In this review, we summarize the current evidence on the mechanisms involved in the modulation of breathlessness in patients with COVID-19. We then offer hypotheses on the possible causes of diminished breathlessness perception in these patients and suggest further areas for research in order to improve knowledge not only of COVID-19 but also of the mechanisms underlying breathlessness more generally.

\section{Mechanisms of Breathlessness Perception}

In comparison with symptoms such as pain, the pathophysiological mechanisms of breathlessness are less well understood [17]. They involve the activation of receptors in the chest wall, lung parenchyma, and airways, as well as the stimulation of the respiratory centre in the brain stem by peripheral and central chemoreceptors [1].

Dyspnoea, like pain, is a subjectively experienced symptom, making measurement of severity challenging. Pain and dyspnoea are both processed in part by the limbic system [18]. These symptoms alert the body to threatening conditions and the potential loss of homeostasis, motivating the subject to seek help and engage in adaptive behaviours [19]. However, individuals commonly experience pain in early life and are therefore able to recognize and describe it, while breathlessness is a symptom experienced less often, and the lack of previous exposure might make its recognition more difficult [19].

The experience of dyspnoea involves sensory and affective dimensions [17]. The severity (sensory intensity) and unpleasantness (affective intensity) of dyspnoea are processed in different areas of the brain [17]. The severity of dyspnoea involves the lateral thalamic system and primary sensory cortex [20]. The unpleasantness of dyspnoea involves activation of the limbic system, the right anterior insula, and the amygdala [20].

In the lungs and lower respiratory tract, unmyelinated $\mathrm{C}$-fibres and small-diameter myelinated $\mathrm{A} \delta$-fibres transmit mechanical and chemical signals to the nucleus of the tractus solitarius in the brain stem, through the afferent vagal nerves. These fibres activate only when triggered by noxious stimuli and are therefore considered as being no- 
ciceptive [21]. After having converged at the nucleus of the tractus solitarius, these fibres are relayed to the brain, more specifically to the somatosensory cortex and other regions of the brain involved in the interpretation of these signals, generating a perception of breathlessness [21].

Carbon dioxide levels are essentially monitored centrally by medullary chemoreceptors, but peripheral chemoreceptors are also involved. On the other hand, blood oxygen levels are monitored peripherally by chemoreceptors located in aortic and carotid bodies. These peripheral signals are transmitted by the glossopharyngeal and vagal nerve to the nucleus of the tractus solitarius where they are relayed to higher brain structures [21].

These stimuli appear to be perceived and interpreted differently depending on a person's past experiences, emotions, and beliefs, irrespective of their objective respiratory status [22-24]. Indeed, the perception of dyspnoea can vary significantly amongst individuals $[25,26]$.

A person's individual behaviour is driven by his/her affective response to the symptom, and in some cases, this can induce an underperception of dyspnoea with consequent failure to recognize the severity of the disease [27]. Higher reporting of dyspnoea often corresponds with higher levels of anxiety, as well as resulting in more frequent hospital admissions $[25,26]$.

Sensory and affective dimensions of breathlessness have different neuronal pathways. Information for affective aspects of breathlessness follows the limbic pathway, travelling from vagal afferents in the lungs and airways to the brainstem and medulla and then projecting to the amygdala and medial dorsal areas of the thalamus, ending in the insula and cingulate cortices. Hypercapnia is a strong stimulus for activation of the limbic pathway, increasing the affective dimension of dyspnoea [28].

Affective dimensions of breathlessness could have a strong influence in subjective ratings of the sensation of breathlessness, leading to overperception of the symptom [29]. Negative emotions have a major impact on breathlessness perception, while positive emotions reduce the intensity of perception of breathlessness [30].

Behavioural consequences of breathlessness have an impact on an individual's daily activities, affecting psychological wellbeing and social life [31]. Avoiding exercise to reduce dyspnoea starts a vicious cycle, potentially leading to a deterioration in general performance status and dependency on care, as well as social isolation, reduced self-esteem, and anxiety. Episodes of sudden breathlessness can be perceived as a near-death experience, leaving patients with posttraumatic stress symptoms [31]. Social limitation, such as limited activity, fear of getting infected, loss of job, financial problems, and caregiver's burden, could become important issues in patients suffering from post-COVID breathlessness.

\section{Contributors to Breathlessness Perception}

There is evidence that the elderly tend to report lower levels of dyspnoea [27]. As well as bringing about physiological changes to sensory organs, such as those involved in hearing and smell, ageing also affects peripheral structures. For example, changes to peripheral receptors in the carotid bodies have been likened to a physiological denervation that appears with age [32]. Peripheral perception of hypercapnia, response to hypoxia, and perception of added restrictive or elastic loads have been shown to be reduced in healthy elderly subjects $[27,33,34]$.

Psychological factors also play a role in breathlessness perception and reporting amongst the elderly. For example, the so-called "positive effect" has been described as the tendency of elderly individuals to withdraw attention from a negative situation and focus on positive information to maintain wellbeing [27]. Fear of hospitalization and loneliness may also contribute, as well as low levels of social support [27].

Diabetes is a frequent comorbidity amongst patients affected by COVID-19 [35-37] and is linked to an increased risk of severe disease, intensive care admission, and mortality [38]. Reasons for increased severity of disease amongst diabetic patients are related to several factors including impairment of the immune response, reduced viral clearance, predisposition to hyperinflammation, increased release of cytokines, and presence of concomitant cardiovascular disease $[39,40]$.

As well as affecting cardiovascular and renal function, diabetes also results in damage to lung tissue, although this is not fully understood [41]. The mechanisms involved in lung dysfunction include glycosylation of lung tissue proteins secondary to hyperglycaemia, oxidative stress, changes in connective tissue, impairment of the surfactant, and damage to alveoli capillaries and other pulmonary vessels [41]. These mechanisms act to impair lung function and pulmonary diffusion capacity. Thickening of the lung basal lamina, noted in autopsies of diabetic patients, is likely to contribute to reduced pulmonary diffusion, while vascular damage will bring about endothelial dysfunction [42]. Reduction in mucociliary clearance also increases vulnerability to infections [41]. Lung function in diabetic patients also suffers as a result of autonomic neuropathy, which can lead to an impaired 
response to hypoxaemia [41]. This may result in delayed reporting of dyspnoea. Infection with SARS-CoV-2 is likely to exacerbate established diabetic mechanisms of inflammation and vascular damage, contributing to the higher levels of adverse outcomes seen in diabetic patients.

\section{Pathophysiology of COVID-19}

Radiological findings on CT scans of patients with COVID-19 include pneumonia and ground glass opacities, as a result of systemic and localized inflammation [43]. Older patients demonstrate a worse clinical picture due, in part, to increased prevalence of comorbidities such as hypertension, diabetes, and cardio-cerebrovascular disease [5]. Mortality rates have been reported as $8.3 \%$ in those aged over 50 years and $18.8 \%$ in those over 80 years [44]. Cardio-cerebrovascular disease and diabetes in particular are important predictors of adverse outcomes [45].

There are three main potential mechanisms by which SARS-CoV-2 could modulate breathlessness: inflammation in the alveoli and lung tissue, thrombosis and associated microclots, and neuroinvasion.

\section{Inflammation in the Alveoli and Lung Tissue}

Inflammation in the alveoli and lung tissue is responsible for impaired gas diffusion capacity and intrapulmonary shunting, causing hypoxaemia with normo- or hypocapnia [46]. Autopsy findings of patients with confirmed COVID-19 have identified diffuse alveolar damage with severe capillary congestion, oedema, and alveolar haemorrhage [47]. Other findings include pneumocyte necrosis, formation of hyaline membranes, and platelet-fibrin thrombi [48]. Inflammation and oedema caused by SARSCoV-2 increases the distance between the alveoli and capillaries [47]. This may contribute to impaired diffusion, whereby carbon dioxide continues to diffuse because of its higher diffusion coefficient, but oxygen diffusion is reduced $[49,50]$. Furthermore, as a consequence of pulmonary oedema and the subsequent reduction in alveolar air space, intrapulmonary shunting occurs due to persistence of arterial perfusion in non-aerated lung tissue [46]. Hypoxaemia, detected by the peripheral chemoreceptors in the aortic bodies, increases the drive in ventilation, inducing hypocapnia [49]. Patients affected by mild to moderate COVID-19 have an appropriate increase in ventilatory drive in response to hypoxaemia, maintaining normal to low levels of carbon dioxide $[3,7,51]$.

Breathlessness and COVID-19: A Call for Research

\section{Thrombosis and Microclots}

Thrombosis and microclots are responsible for an increase in ventilation/perfusion mismatch and physiological dead space (VD), that is, normally ventilated but poorly perfused zones. Redistribution of perfusion to the unaffected vascular bed decreases the ratio of air reaching the alveoli per minute to cardiac output (VA/Q) and leads to hypoxaemia. If the impact on the vascular bed is important and the ratio of dead space on tidal volume is high (VD/VT), this can per se limit the elimination of $\mathrm{CO}_{2}$ and cause hypercapnia.

There is evidence that infection with SARS-CoV-2 causes activation of the coagulation cascade and subsequent endothelial damage, resulting in a prothrombotic state $[47,52,53]$. This has been widely observed in patients with COVID-19 $[47,54,55]$, with coagulation activation and endothelial dysfunction recognized as predictors of worse outcome and death $[54,56,57]$.

Similar prothrombotic responses were observed in other coronaviruses such as SARS-CoV-1 and MERS$\mathrm{CoV}[57,58]$. These responses may be an attempt to prevent diffuse alveolar haemorrhage, yet they act to worsen respiratory failure through the extensive formation and deposition of fibrin $[57,58]$. Multiple thrombi in pulmonary vessels can impair perfusion by increasing the functional dead space in the alveoli [50].

\section{Neuroinvasion}

As with other coronaviruses, SARS-CoV-2 has a neuroinvasive potential and has been identified in brain tissue in post-mortem studies [59-63]. One proposed pathway through which SARS-CoV-2 can reach the brain involves entry via the nasal epithelium and subsequently the peripheral nervous pathway via cranial nerves $[15,64$, 65].

A second and likely simultaneous mechanism by which the virus enters the brain is by first entering the bloodstream or lymph system via the cellular receptor angiotensin-converting enzyme 2 located in vessels inside the airway mucosa $[12,66]$ and then passing to the central nervous system through the blood-brain barrier [66].

Entry via cranial nerve I (olfactory) is supported by evidence of similar neural invasion in other coronaviruses and by reports of olfactory symptoms early in the disease trajectory of patients infected by SARS-CoV-2 [64]. Many patients with COVID-19 have reported anosmia and dysgeusia [67], which may also result from invasion of cranial nerves VII (facial), IX (glossopharyngeal), and $\mathrm{X}$ (vagus). On the other hand, these three nerves carry information to the nucleus of the solitary tract in the me-

Respiration 2021;100:1016-1026 
dulla of the brainstem. The nucleus of the solitary tract is located proximally to respiratory centres in the brainstem. Impairment of these nervous pathways due to SARS-CoV-2 infection may alter the function of the respiratory centres in the medulla and result in neurogenic breathlessness [12, 64].

Among the neurological complications of COVID-19, delirium and altered consciousness are common [68-71]. It is estimated that up to one-third of patients with COVID-19 will develop delirium, with a greater risk in the intensive care population and increased mortality, especially in older adults [69-74]. The aetiology of delirium in the context of COVID-19 is multifactorial due to the severity of the illness, metabolic changes (hypoxaemia, dehydration, and fever), use of sedative medications, social isolation, and hospital environment with staff wearing personal protective equipment. Neuroinvasion should be considered as a relevant contributing factor $[70,75]$. Furthermore, an unusual acute encephalopathy has been described in COVID-19 patients [76-78]. The clinical presentation of this encephalopathy is heterogeneous from subdelirium to coma and may even precede the onset of respiratory symptoms [77]. The pathophysiological mechanism of this encephalopathy remains to be determined: although some cases of true encephalitis have been described in the context of COVID-19 [79], the presence of the virus has not been demonstrated by RTPCR in this encephalopathy, and the normality of the cerebrospinal fluid white cell count suggests a mechanism independent from the direct presence of the virus [76]. Biological features suggestive of a blood-brain barrier disruption in addition to neurological signs in favour of an intracerebral endotheliitis may suggest an inflammatory mechanism for this acute encephalopathy [78]. However, this remains a hypothesis at this stage.

\section{Hypotheses for the Neurological Alteration of Breathlessness Perception in COVID-19 Patients}

Perception of breathlessness in all disease states, including COVID-19, is multifactorial. However, the precise sensory and neural mechanisms involved in the perception of breathlessness, and an individual's response to that breathlessness, still remain unclear $[1,16,17]$. As demonstrated above, there appears to be a strong cognitive component to the perception of breathlessness in any disease state, and this is likely to play a significant role in the perception of breathlessness in COVID-19, especially in patients with acute encephalopathy.
The strength of the impact of the cognitive component on breathlessness perception in any individual is likely to vary between different subgroups of patients. Patients with COVID-19 present a variety of respiratory phenotypes, including decreased oxygen saturations, tachypnoea, and a wide range of intrapulmonary pathologies, which do not appear to be correlated closely with the presence or absence of breathlessness [80-82]. Indeed, as observed in clinical practice, subgroups of patients with severe chronic obstructive pulmonary disease may have a very low level of dyspnoea despite very severe desaturation during exertion or even resting hypoxaemia. This is also noted in patients with right-to-left anatomic shunts (i.e., Eisenmenger syndrome). Furthermore, the clinical spectrum of neurological symptoms of COVID-19 patients is broad, ranging from the absence of any cognitive symptoms to coma.

We propose that the perception of breathlessness in patients with COVID-19 may be altered by damage to neural processing of breathlessness perception in the brain, which may in itself be similar to the cortical modulation of the perception of pain. As the sensory and affective aspects of breathlessness are mediated by the sensory and limbic and insular cortices, respectively, it follows that the neural processing of breathlessness involves crosstalk between these two areas. We propose that cortical processing and modulation of breathlessness perception could be changed by SARS-CoV-2 via three different mechanisms:

1. SARS-CoV-2 could interrupt afferent sensory signalling pathways, rendering the cortical structures responsible for processing the sensory aspects of breathlessness unable to receive afferent inputs from the brainstem. It may also be possible that direct damage from the virus to mechano- or irritant receptors in the respiratory tract and/or the chest wall prevents afferent signals from reaching the brainstem and then being relayed to higher brain structures.

2. SARS-CoV-2 could interfere with the ability of cortical structures to recognize or process afferent sensory breathlessness signals from the brainstem. This could happen either directly by the effect of SARS-CoV-2 on nerve fibres or indirectly, through inflammatory acute encephalopathy or cerebrovascular complications, such as ischaemic or haemorrhagic stroke $[76,83]$.

3. The cortical structures involved in the perception of breathlessness could have a potentiating effect on the perception of breathlessness, as with pain, which could be interrupted by SARS-CoV-2. Experimental inhalation of $35 \% \mathrm{CO}_{2}$ has been shown to induce dyspnoea- 
Fig. 1. Timeline to the development of breathlessness in patients suffering from COVID-19 pneumonia. Neurological symptoms such as anosmia and hypogeusia are present early in the disease and reflect a possible neuroinvasion of SARS-CoV-2. In patients developing severe COVID-19, physiological changes include the presence of inflammation in the lungs, abnormalities in diffusion, thrombosis, and a mismatch in ventilation/perfusion, generally appearing after the first 7 days of infection. Breathlessness becomes more present at this stage and can persist in the post-COVID phase. COVID-19, coronavirus disease 19; SARS-CoV-2, severe acute respiratory syndrome coronavirus 2 .

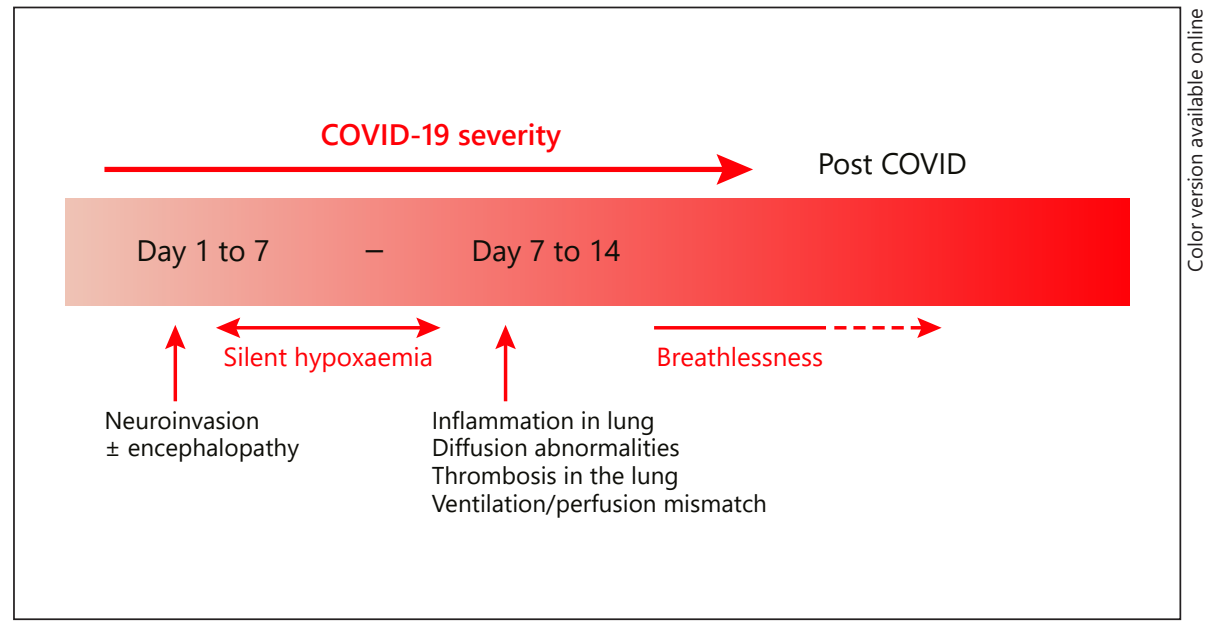

related panic attacks in patients with bilateral amygdala damage, with self-reported levels of panic and fear significantly higher than in the neurologically intact comparison group. This could suggest that $\mathrm{CO}_{2}$ directly activates extra-limbic brain structures, which are then downregulated by the amygdala.

The absolute or relative importance of any of these three proposed mechanisms is not yet clear, and any combination of these three mechanisms could be at play. In addition, the varying extent of lung and brain damage may also contribute to the alteration of breathlessness perception, as discussed in the aforementioned hypotheses [84].

However, it is also clear that many patients with COVID-19 do develop breathlessness and that the prevalence of breathlessness appears higher in patients with more severe lung disease and with worse prognoses [80, $81,85]$. We hypothesize that the direct neuroinvasive effects of SARS-CoV-2 could mitigate, or reduce, the perception of breathlessness, by one or many of the three proposed mechanisms given above. In contrast, indirect effects of SARS-CoV-2 on the cardiorespiratory system, causing interstitial inflammation and thrombosis, will damage the ventilatory ability of the lungs, ultimately leading to failure of gas exchange and organ failure.

We propose that time plays a factor, with neuronal damage and loss of breathlessness perception predominating in the earlier stage of the disease. As the neurological complications, such as the acute encephalopathy, may even precede the respiratory symptoms, we can hypothesize that the "happy" or "silent hypoxaemia" phenomenon may represent a preclinical symptom of the virus. For patients with mild disease, this phenotype will predominate throughout the course of the disease. If

Breathlessness and COVID-19: A Call for Research

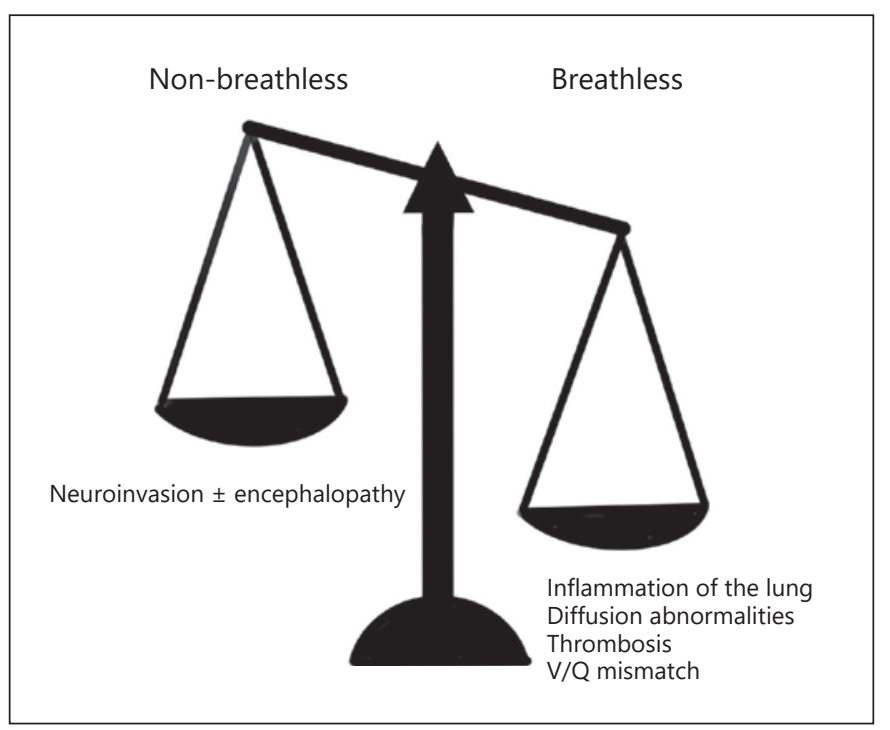

Fig. 2. Breathlessness in COVID-19: a balance between factors influencing symptom perception. Neuroinvasion and encephalopathy appears to reduce breathlessness early on in the disease. In more severe cases, as the disease progresses, inflammation, diffusion alteration, thrombosis, and V/Q mismatch override the potential breathlessness perception alteration caused by the neuroinvasion of SARS-CoV-2, and patients become breathless. COVID-19, coronavirus disease 19; SARS-CoV-2, severe acute respiratory syndrome coronavirus $2 ; \mathrm{V} / \mathrm{Q}$, ventilation/perfusion.

breathlessness emerges, as noted in the case of more severe disease, this will occur later on, once cardio-pulmonary damage has become established [14]. Figure 1 summarizes this timeline.

Finally, we propose that the impact of SARS-CoV-2 on the central neural processing of breathlessness lies at the opposing end of an equilibrium to the effects of cardiore- 
spiratory inflammation and thrombosis. For those patients with mild or early disease, reduction of breathlessness perception resulting from the interference of SARSCoV-2 on brain function will prevail, leading to the apparent disconnection seen between physiological state and breathlessness. For patients with severe disease, damage to the ventilatory capacity of the lungs tips the balance in favour of breathlessness, as the body can no longer ignore the physiological signals resulting from impending organ failure. It is likely that breathlessness perception increases as lung function decreases, and the most severely affected are rendered unable to rate their symptoms by virtue of being ventilated under sedation (shown in Fig. 2).

\section{Perspectives and Research Opportunities}

\section{Discussion}

The pathophysiology of breathlessness involves an interplay between multiple complex mechanisms among the brain-lung interaction. These include mechanical, neurological, and cognitive processes. Individual, nonCOVID-19-related patient factors including age and comorbidities such as diabetes also play a role, as well as social and environmental factors. In the case of $\mathrm{CO}$ VID-19, the lack of perceived breathlessness in hypoxic patients has been widely observed, adding further inscrutability to the pathways behind this symptom.

As has been previously stated, the range of breathlessness reported in studies is wide. Some of this variability may be explained by the different tools used for breathlessness evaluation, as they were not specified in the majority of studies looking at symptom prevalence in $\mathrm{CO}$ VID-19. Different tools could have been used such as the Modified Borg Scale or the Numerical Rating Scale [86]. However, it is also possible that breathlessness was documented in medical files according to the caring physicians' or researchers' evaluation based on objective clinical signs such as tachypnoea, facial expression, or the use of accessory respiratory muscles. Dyspnoea is subjective, and physical or clinical signs may under- or, in this case, overestimate patients' discomfort [87]. Furthermore, the severity of breathlessness was not documented in meta-analyses, it was either present or absent, and therefore the clinical impact of dyspnoea could not be evaluated. Finally, breathlessness is a common symptom in the general population, and patients may develop COVID-19 already suffering from breathlessness. This could lead to an overestimation of the number of pa- tients experiencing dyspnoea related to COVID-19. Therefore, using variation in breathlessness could instead provide a more accurate measure of the dyspnoea caused by COVID-19 and should be considered in further studies.

We have drawn on the currently available literature to discuss the mechanisms of breathlessness perception and how these may be affected during SARS-CoV-2 infection. These include inflammation of lung tissues, development of microthrombi in the pulmonary circulation, and neurological complications, such as cerebrovascular events or acute encephalopathy. We have proposed an additional three main hypotheses, based on neuropsychological processes, to explain the phenomenon of diminished breathlessness perception that has been observed in COVID-19 patients, as well as proposing relationships between cognitive and physiological components of breathlessness and how they interact over time. Yet, further evidence is needed to validate these hypotheses.

Recent reports have highlighted the prevalence of dyspnoea in post-COVID-19 follow-ups [88]. It is interesting to note that although most symptoms seem to disappear with time, dyspnoea and fatigue are still reported 2 months after the onset of the first COVID-19 symptoms [89].

Although it has been shown that the severity of postCOVID-19 symptoms is related to the severity of the acute COVID-19 phase, it is not yet clear which patients will present with persistent dyspnoea [88]. Many patients have been experiencing shortness of breath and other related symptoms that start or remain beyond the initial period of acute infection, such as chronic cough, chest tightness, cognitive dysfunction, and fatigue, commonly referred to as "long COVID." It is not yet known if patients that did not present with dyspnoea in the acute COVID-19 phase will eventually develop dyspnoea after the end of the disease. This could indicate that SARS-CoV-2 may have an impact on breathlessness perception. An alternative hypothesis for explaining this emerging breathlessness in patients without dyspnoea during the acute phase may refer to the complex and unsolved pathophysiological mechanisms of long COVID, such as immunologic and inflammatory reactions in response to the acute infection.

Fatigue is closely related to breathlessness, and the mechanisms of COVID-induced fatigue could be extrapolated to further our understanding of COVID-related breathlessness. For instance, the presence of mental and physical fatigue combined or not with a dysexecutive syndrome appears to be a result of the impact of COVID-19 
on brain functioning. Literature suggests that fatigue could be underlined by functional impairment of the main inhibitory circuits in the primary motor cortex, demonstrated by transcranial magnetic stimulation [90]. Transcranial magnetic stimulation findings show evidence for the hypothesis that COVID-19 may cause an impairment of GABA-ergic intracortical circuits, and it is possible that COVID-19 could have similar effects on cortical breathlessness pathways [90-92].

Finally, although reports have shown that patients are at risk of developing chronic pain in the post-COVID-19 phase $[93,94]$, it has been recently suggested that acute SARS-CoV-2 infection may reduce nociceptive pain perception [95]. Indeed, although evidence is still lacking at this stage, SARS-CoV-2 has been shown to inhibit neuropathic pain signalling by binding to neuroliptin-1 receptors on sensory neurones in animal models [96]. In this case, pain modulation seems to arise from peripheral nerves and not intracerebral signalling. Although these results remain to be confirmed, they may provide useful insight into the ways in which not only pain but also possibly breathlessness is affected by this virus.

\section{Limitations}

COVID-19 is a new disease, and knowledge is continuously and rapidly evolving. Our article is therefore limited to what is known so far from the currently available published observational literature and small number of post-mortem studies. Furthermore, the authors have not conducted a quality assessment of the literature presented in this article.

\section{Implications for Clinical Practice}

The phenomenon of diminished breathlessness perception in COVID-19 patients involves mechanisms that could potentially be taken advantage of in order to improve management of dyspnoea in the future. Furthering our knowledge of the physiological pathways that lead to patient variability in the perception of breathlessness may allow differentiation between those more or less likely to develop or experience breathlessness and target finite resources. Special attention should be paid to patients who do not feel breathless as their clinical state could deteriorate rapidly.

The response to the COVID-19 pandemic has involved a multidisciplinary approach, encompassing a multiskilled taskforce including personnel from internal medicine, geriatrics, respiratory, neurology, and primary, critical, and palliative care, as well as pathologists. By encouraging integrated care among these disciplines, the
COVID-19 pandemic has provided the opportunity to build links between specialities.

The literature presented here has implications across this multidisciplinary taskforce. An integrated approach is precisely what is needed in building our understanding of this disease and the complex physiology underpinning its symptoms. This will also have implications for non-COVID-19 patients, including those with cancer, lung disease, heart failure, and neurodegenerative disorders, who experience similar distressing symptoms of breathlessness.

\section{Implications for Research}

By creating an unusual symptom response, COVID-19 questions our understanding of the mechanisms of breathlessness and its possible pathways, providing an opportunity for research into the management of a symptom that is both debilitating and difficult to treat. There is no gold standard for measuring breathlessness [97]. Validated tools can be classified in three categories. Unidimensional breathlessness tools such as the Visual Analogue Scale, the Numerical Rating Scale, or the Modified Borg Scale are commonly used. However, these unidimensional scales are limited in the fact that they only record dyspnoea intensity. Multidimensional tools allow a deeper evaluation as they may include other domains such as physical, emotional, or other domains of healthrelated quality of life, as with the Dyspnoea-12 Scale or dyspnoea scales from disease-specific instruments such as the Chronic Respiratory Questionnaire [98-100]. Other tools enable the evaluation of specific domains such as the Medical Research Council Dyspnoea Scale which measures activity limitation related to breathlessness [97, $101,102]$. Although dyspnoea is a subjective symptom, tools that do not require patient participation have been validated and should be used [103]. Furthermore, a more thorough study of the correlation between patients' reports of dyspnoea and the severity of the disease as can be measured with blood gases and biological and physical markers should also be considered.

The evidence presented in this article is extensive, describing important considerations pertinent to a multidisciplinary audience. It is therefore possible to propose several research questions, relating to both pathophysiological and patient factors, that are relevant to a variety of disciplines. Further research should consider using validated uni- and multidimensional dyspnoea measuring tools in order to quantify the evolution of breathlessness intensity throughout the course of the disease and in the post-COVID phase. Given the neuroinvasive potential of SARS-CoV-2, functional MRIs could be used to gain a 
deeper understanding of the difference in brain activity seen amongst COVID-19 patients and how this contributes to the variations in breathlessness perception. Finally, pathologists and fundamental researchers should further investigate the neurotropic mechanisms of SARS-CoV-2 and how these might influence breathlessness perception.

\section{Conclusion}

Breathlessness is a debilitating and frequent symptom amongst patients with advanced disease. As several reports have now shown that dyspnoea is frequently low or absent in patients suffering from COVID-19, despite severe physiological and anatomical changes in the lungs, it has become clear that COVID-19 affects the way breathlessness is perceived.

As patients with mild COVID-19 still respond physiologically to hypoxaemia, by increasing ventilatory drive, we hypothesize that higher cortical structures are involved in the alteration of breathlessness perception either by directly affecting the interpretation of afferent signals or by altering the top-down regulation of breathlessness. Furthermore, we believe there is a strong correlation between breathlessness and the progressive level of damage that occurs in the lungs.

At present, many questions remain, and future research should focus on clarifying and improving our knowledge of this phenomenon. A multidisciplinary approach will be crucial in gaining knowledge about the pathophysiological mechanisms involved in the alteration of breathlessness in COVID-19 patients.

\section{Acknowledgments}

The authors would like to thank all the patients and families who are contributing to the increase in knowledge surrounding COVID-19.

\section{Conflict of Interest Statement}

The authors have no conflicts of interest to declare.

\section{Funding Sources}

This research did not receive any specific grant from funding agencies in the public, commercial, or not-for-profit sectors.

\section{Author Contributions}

L.H., S.C., I.S., R.E., and E.A. wrote the manuscript. All authors reviewed the literature and edited and commented on the manuscript. S.C. created the figures. All the authors reviewed and approved the final manuscript to be published.

\section{References}

1 Parshall MB, Schwartzstein RM, Adams L, Banzett RB, Manning HL, Bourbeau J, et al. An official American Thoracic Society statement: update on the mechanisms, assessment, and management of dyspnea. Am J Respir Crit Care Med. 2012 Feb 15;185(4):435-52.

2 Zhu Z, Lian X, Su X, Wu W, Marraro GA, Zeng Y. From SARS and MERS to COVID-19: a brief summary and comparison of severe acute respiratory infections caused by three highly pathogenic human coronaviruses. Respir Res. 2020 Aug 27;21(1):224.

3 Guan WJ, Ni ZY, Hu Y, Liang WH, Ou CQ, $\mathrm{He}$ JX, et al. Clinical characteristics of coronavirus disease 2019 in China. N Engl J Med. 2020 30;382(18):1708-20.

4 Chen L, Liu HG, Liu W, Liu J, Liu K, Shang J, et al. Analysis of clinical features of 29 patients with 2019 novel coronavirus pneumonia. Zhonghua Jie He He Hu Xi Za Zhi. 2020 Feb 6;43(0):E005.

5 Rodriguez-Morales AJ, Cardona-Ospina JA, Gutiérrez-Ocampo E, Villamizar-Peña R, Holguin-Rivera Y, Escalera-Antezana JP, et al. Clinical, laboratory and imaging features of COV-
ID-19: a systematic review and meta-analysis. Travel Med Infect Dis. 2020 Mar;34:101623.

6 Li LQ, Huang T, Wang YQ, Wang ZP, Liang Y, Huang TB, et al. COVID-19 patients' clinical characteristics, discharge rate, and fatality rate of meta-analysis. J Med Virol. 2020;92(6):577-83.

7 Huang C, Wang Y, Li X, Ren L, Zhao J, Hu Y, et al. Clinical features of patients infected with 2019 novel coronavirus in Wuhan, China. Lancet Lond Engl. 2020 15;395(10223):497-506.

$8 \mathrm{Hu}$ Y, Sun J, Dai Z, Deng H, Li X, Huang Q, et al. Prevalence and severity of corona virus disease 2019 (COVID-19): a systematic review and meta-analysis. J Clin Virol. 2020; 127:104371.

9 Chen N, Zhou M, Dong X, Qu J, Gong F, Han $\mathrm{Y}$, et al. Epidemiological and clinical characteristics of 99 cases of 2019 novel coronavirus pneumonia in Wuhan, China: a descriptive study. Lancet. 2020 15;395(10223):507-13.

10 Shi L, Wang Y, Wang Y, Duan G, Yang H. Dyspnea rather than fever is a risk factor for predicting mortality in patients with $\mathrm{COV}$ ID-19. J Infect. 2020 May 15;81:647-79.
11 Tobin MJ, Laghi F, Jubran A. Why COVID-19 silent hypoxemia is baffling to physicians. Am J Respir Crit Care Med. 2020 Aug 1;202(3):356-60.

12 Li YC, Bai WZ, Hashikawa T. The neuroinvasive potential of SARS-CoV2 may play a role in the respiratory failure of COVID-19 patients. J Med Virol. 2020 Feb 27;92:552-55.

13 Coen M, Allali G, Adler D, Serratrice J. Hypoxemia in COVID-19; Comment on: The neuroinvasive potential of SARS-CoV2 may play a role in the respiratory failure of COVID-19 patients. J Med Virol. 2020 May 17;92: 1705-6.

14 Dhont S, Derom E, Van Braeckel E, Depuydt $\mathrm{P}$, Lambrecht BN. The pathophysiology of 'happy' hypoxemia in COVID-19. Respir Res. 2020 Jul 28;21(1):198.

15 Das G, Mukherjee N, Ghosh S. Neurological Insights of COVID-19 Pandemic. ACS Chem Neurosci. 2020 06;11(9):1206-9.

16 Manning HL, Schwartzstein RM. Pathophysiology of dyspnea. Epstein FH, editor. N Engl J Med. 1995 Dec 7;333(23):1547-53. 
17 Lansing RW, Gracely RH, Banzett RB. The multiple dimensions of dyspnea: review and hypotheses. Respir Physiol Neurobiol. 2009 May 30;167(1):53-60.

18 Schön D, Rosenkranz M, Regelsberger J, Dahme B, Büchel C, von Leupoldt A. Reduced perception of dyspnea and pain after right insular cortex lesions. Am J Respir Crit Care Med. 2008 Dec;178(11):1173-9.

19 Banzett RB. Dyspnea and pain: similarities and constrasts between two very unpleasant sensations. APS Bull. 2001;11(1).

20 von Leupoldt A, Sommer T, Kegat S, Baumann HJ, Klose H, Dahme B, et al. The unpleasantness of perceived dyspnea is processed in the anterior insula and amygdala. Am J Respir Crit Care Med. 2008 May 1;177(9):1026-32.

21 González-Duarte A, Norcliffe-Kaufmann L. Is "happy hypoxia" in COVID-19 a disorder of autonomic interoception? A hypothesis. Clin Auton Res Off J Clin Auton Res Soc. 2020;30(4):331-3.

22 Currow DC, Higginson IJ, Johnson MJ. Breathlessness-current and emerging mechanisms, measurement and management: a discussion from an European Association of Palliative Care workshop. Palliat Med. 2013 Dec;27(10):932-8.

23 Spathis A, Booth S, Moffat C, Hurst R, Ryan $\mathrm{R}$, Chin $\mathrm{C}$, et al. The breathing, thinking, functioning clinical model: a proposal to facilitate evidence-based breathlessness management in chronic respiratory disease. NPJ Prim Care Respir Med. 2017 Apr 21;27(1):27.

24 Chin C, Booth S. Managing breathlessness: a palliative care approach. Postgrad Med J. 2016 Jul;92(1089):393-400.

25 Carpio C, Villasante C, Galera R, Romero D, de Cos A, Hernanz A, et al. Systemic inflammation and higher perception of dyspnea mimicking asthma in obese subjects. J Allergy Clin Immunol. 2016 Mar;137(3):718-26.e4.

26 Scioscia G, Blanco I, Arismendi E, Burgos F, Gistau C, Foschino Barbaro MP, et al. Different dyspnoea perception in COPD patients with frequent and infrequent exacerbations. Thorax. 2017 Feb;72(2):117-21.

27 Petersen S, von Leupoldt A, Van den Bergh O. Geriatric dyspnea: doing worse, feeling better. Ageing Res Rev. 2014 May;15:94-9.

28 von Leupoldt A, Dahme B. Cortical substrates for the perception of dyspnea. Chest. $2005 \mathrm{Jul}$; 128(1):345-54.

29 von Leupoldt A, Ambruzsova R, Nordmeyer $\mathrm{S}$, Jeske N, Dahme B. Sensory and affective aspects of dyspnea contribute differentially to the Borg scale's measurement of dyspnea. Respiration. 2006;73(6):762-8.

30 von Leupoldt A, Mertz C, Kegat S, Burmester S, Dahme B. The impact of emotions on the sensory and affective dimension of perceived dyspnea. Psychophysiology. 2006 Jul;43(4):382-6.

31 Janssen DJ, Wouters EF, Spruit MA. Psychosocial consequences of living with breathlessness due to advanced disease. Curr Opin Support Palliat Care. 2015 Sep;9(3):232-7.

32 Di Giulio C. Ageing of the carotid body. J Physiol. 2018;596(15):3021-7.
33 Kronenberg RS, Drage CW. Attenuation of the ventilatory and heart rate responses to hypoxia and hypercapnia with aging in normal men. J Clin Invest. 1973 Aug;52(8):1812-9.

34 Janssens JP, Pache JC, Nicod LP. Physiological changes in respiratory function associated with ageing. Eur Respir J. 1999 Jan;13(1):197-205.

35 Singh AK, Gupta R, Ghosh A, Misra A. Diabetes in COVID-19: prevalence, pathophysiology, prognosis and practical considerations. Diabetes Metab Syndr. 2020 Apr 9;14(4):303-10.

36 Riddle MC, Buse JB, Franks PW, Knowler WC, Ratner RE, Selvin E, et al. COVID-19 in people with diabetes: urgently needed lessons from early reports. Diabetes Care. 2020 May $14 ; 43: 1378-81$.

37 Gupta R, Hussain A, Misra A. Diabetes and COVID-19: evidence, current status and unanswered research questions. Eur J Clin Nutr. 2020 May 13;74:864-70.

38 Yan Y, Yang Y, Wang F, Ren H, Zhang S, Shi X, et al. Clinical characteristics and outcomes of patients with severe COVID-19 with diabetes. BMJ Open Diabetes Res Care. 2020;8(1):e001343.

39 Wang CP, Lorenzo C, Espinoza SE. Frailty attenuates the impact of metformin on reducing mortality in older adults with type 2 diabetes. J Endocrinol Diabetes Obes. 2014;2(2):1031.

40 Muniyappa R, Gubbi S. COVID-19 pandemic, coronaviruses, and diabetes mellitus. Am J Physiol Endocrinol Metab. 2020 01;318(5): E736-41.

41 Kolahian S, Leiss V, Nürnberg B. Diabetic lung disease: fact or fiction? Rev Endocr Metab Disord. 2019;20(3):303-19.

42 Weynand B, Jonckheere A, Frans A, Rahier J. Diabetes mellitus induces a thickening of the pulmonary basal lamina. Respiration. 1999; 66(1):14-9.

43 Rothan HA, Byrareddy SN. The epidemiology and pathogenesis of coronavirus disease (COVID-19) outbreak. J Autoimmun. 2020;109: 102433.

44 Niu S, Tian S, Lou J, Kang X, Zhang L, Lian H, et al. Clinical characteristics of older patients infected with COVID-19: a descriptive study. Arch Gerontol Geriatr. 2020 Apr 10;89: 104058.

45 Tian W, Jiang W, Yao J, Nicholson CJ, Li RH, Sigurslid $\mathrm{HH}$, et al. Predictors of mortality in hospitalized COVID-19 patients: a systematic review and meta-analysis. J Med Virol. 2020 May 22;92:1875-83.

46 Gattinoni L, Chiumello D, Caironi P, Busana M, Romitti F, Brazzi L, et al. COVID-19 pneumonia: different respiratory treatments for different phenotypes? Intensive Care Med. 2020;46(6):1099-102.

47 Menter T, Haslbauer JD, Nienhold R, Savic S, Hopfer H, Deigendesch N, et al. Post-mortem examination of COVID19 patients reveals diffuse alveolar damage with severe capillary congestion and variegated findings of lungs and other organs suggesting vascular dysfunction. Histopathology. 2020 May 4;77:198-209.

48 Carsana L, Sonzogni A, Nasr A, Rossi R, Pellegrinelli A, Zerbi $\mathrm{P}$, et al. Pulmonary post- mortem findings in a large series of COVID-19 cases from Northern Italy. Lancet Infect Dis. 2020;20:1135-1140.

49 Ward J. Physiology of breathing II. Surgery. 2005 Dec;23(12):430-5.

50 West JB, Luks A. West's respiratory physiology: the essentials. 10th ed. Philadelphia, PA: Wolters Kluwer; 2016. p. 238.

51 Lechien JR, Chiesa-Estomba CM, Place S, Van Laethem Y, Cabaraux P, Mat Q, et al. Clinical and epidemiological characteristics of 1420 European patients with mild-to-moderate coronavirus disease 2019. J Intern Med. 2020 Apr 30;288:335-44.

52 Magro C, Mulvey JJ, Berlin D, Nuovo G, Salvatore S, Harp J, et al. Complement associated microvascular injury and thrombosis in the pathogenesis of severe COVID-19 infection: a report of five cases. Transl Res J Lab Clin Med. 2020 Apr 15;220:113.

53 Ciceri F, Beretta L, Scandroglio AM, Colombo S, Landoni G, Ruggeri A, et al. Microvascular COVID-19 lung vessels obstructive thromboinflammatory syndrome (MicroCLOTS): an atypical acute respiratory distress syndrome working hypothesis. Crit Care Resusc. 2020 Apr 15;22:957.

54 Lodigiani C, Iapichino G, Carenzo L, Cecconi M, Ferrazzi P, Sebastian T, et al. Venous and arterial thromboembolic complications in COVID-19 patients admitted to an academic hospital in Milan, Italy. Thromb Res. 2020;191:9-14.

55 Middeldorp S, Coppens M, van Haaps TF, Foppen M, Vlaar AP, Müller MCA, et al. Incidence of venous thromboembolism in hospitalized patients with COVID-19. J Thromb Haemost. 2020 May 5;18:19952002.

56 Connors JM, Levy JH. COVID-19 and its implications for thrombosis and anticoagulation. Blood. 2020 Jun 4;135(23):2033-40.

57 Spiezia L, Boscolo A, Poletto F, Cerruti L, Tiberio I, Campello E, et al. COVID-19-related severe hypercoagulability in patients admitted to intensive care unit for acute respiratory failure. Thromb Haemost. 2020 Jun;120(6):998-1000.

58 Giannis D, Ziogas IA, Gianni P. Coagulation disorders in coronavirus infected patients: COVID-19, SARS-CoV-1, MERS-CoV and lessons from the past. J Clin Virol. 2020 Jun; 127:104362.

59 Lai CC, Shih TP, Ko WC, Tang HJ, Hsueh PR Severe acute respiratory syndrome coronavirus 2 (SARS-CoV-2) and coronavirus disease-2019 (COVID-19): the epidemic and the challenges. Int J Antimicrob Agents. 2020 Mar;55(3):105924.

60 Li K, Wohlford-Lenane C, Perlman S, Zhao J, Jewell AK, Reznikov LR, et al. Middle east respiratory syndrome coronavirus causes multiple organ damage and lethal disease in mice transgenic for human dipeptidyl peptidase 4 . J Infect Dis. 2016 Mar 1;213(5):712-22.

61 Baig AM, Khaleeq A, Ali U, Syeda H. Evidence of the COVID-19 virus targeting the CNS: tissue distribution, host-virus interaction, and proposed neurotropic mechanisms. ACS Chem Neurosci. 2020 01;11(7):995-8. 
62 Puelles VG, Lütgehetmann M, Lindenmeyer MT, Sperhake JP, Wong MN, Allweiss L, et al. Multiorgan and renal tropism of SARSCoV-2. N Engl J Med. 2020 May 13;383:59092.

63 Matschke J, Lütgehetmann M, Hagel C, Sperhake JP, Schröder AS, Edler C, et al. Neuropathology of patients with COVID-19 in Germany: a post-mortem case series. Lancet $\mathrm{Neu}-$ rol. 2020 Nov;19(11):919-29.

64 Baig AM. Neurological manifestations in COVID-19 caused by SARS-CoV-2. CNS Neurosci Ther. 2020;26(5):499-501.

65 Butowt R, Bilinska K. SARS-CoV-2: olfaction, brain infection, and the urgent need for clinical samples allowing earlier virus detection. ACS Chem Neurosci. 2020 06;11(9):1200-3.

66 Paybast S, Emami A, Koosha M, Baghalha F. Novel coronavirus disease (COVID-19) and central nervous system complications: what neurologist need to know. Acta Neurol Taiwan. 2020 Mar 30;29(1)(1):24-31.

67 Marinho PM, Marcos AAA, Romano AC, Nascimento H, Belfort R. Retinal findings in patients with COVID-19. Lancet. 2020 23 395(10237): 1610.

68 Lovell N, Maddocks M, Etkind SN, Taylor K, Carey I, Vora V, et al. Characteristics, symptom management, and outcomes of 101 patients with COVID-19 referred for hospital palliative care. J Pain Symptom Manage. 2020 Apr 20;60:e77-81.

69 Mao L, Jin H, Wang M, Hu Y, Chen S, He Q, et al. Neurologic Manifestations of hospitalized patients with coronavirus disease 2019 in Wuhan, China. JAMA Neurol. 2020 Apr 10;77:68390.

70 O'Hanlon S, Inouye SK. Delirium: a missing piece in the COVID-19 pandemic puzzle. Age Ageing. 2020 May 6;49:49798.

71 Helms J, Kremer S, Merdji H, Clere-Jehl R, Schenck M, Kummerlen C, et al. Neurologic features in severe SARS-CoV-2 infection. N Engl J Med. 2020 04;382(23):2268-70.

72 Garcez FB, Aliberti MJR, Poco PCE, Hiratsuka M, Takahashi Sde F, Coelho VA, et al. Delirium and adverse outcomes in hospitalized patients with COVID-19. J Am Geriatr Soc. 2020 Aug 24;68:2440-6.

73 Marengoni A, Zucchelli A, Grande G, Fratiglioni L, Rizzuto D. The impact of delirium on outcomes for older adults hospitalised with $\mathrm{CO}$ VID-19. Age Ageing. 2020 Aug 20;49:923-6.

74 Mendes A, Serratrice C, Herrmann FR, Genton L, Périvier S, Scheffler M, et al. Predictors of in-hospital mortality in older patients With COVID-19: the COVID age study. J Am Med Dir Assoc. 2020 Nov;21(11):1546-1554.e3.

75 Rogers JP, Chesney E, Oliver D, Pollak TA, McGuire P, Fusar-Poli P, et al. Psychiatric and neuropsychiatric presentations associated with severe coronavirus infections: a systematic review and meta-analysis with comparison to the COVID-19 pandemic. Lancet Psychiatry. 2020 May 18;7:61127.

76 Koralnik IJ, Tyler KL. COVID-19: a global threat to the nervous system. Ann Neurol. 2020;88(1):1-11.

77 Pilotto A, Odolini S, Masciocchi S, Comelli A, Volonghi I, Gazzina S, et al. Steroid-respon- sive encephalitis in coronavirus disease 2019 Ann Neurol. 2020 May 17;88:423-7.

78 Pugin D, Vargas MI, Thieffry C, Schibler M, Grosgurin O, Pugin J, et al. COVID-19-related encephalopathy responsive to high-dose glucocorticoids. Neurology. 2020 22;95(12):5436

79 Bernard-Valnet R, Pizzarotti B, Anichini A, Demars Y, Russo E, Schmidhauser M, et al. Two patients with acute meningoencephalitis concomitant with SARS-CoV-2 infection. Eur J Neurol. 2020 May 7;27:e434.

80 Lechien JR, Chiesa-Estomba CM, De Siati DR, Horoi M, Le Bon SD, Rodriguez A, et al. Olfactory and gustatory dysfunctions as a clinical presentation of mild-to-moderate forms of the coronavirus disease (COVID-19): a multicenter European study. Eur Arch Otorhinolaryngol. 2020 Aug;277(8):2251-61.

81 Wang D, Hu B, Hu C, Zhu F, Liu X, Zhang J, et al. Clinical characteristics of 138 hospitalized patients with 2019 novel coronavirus-infected pneumonia in Wuhan, China. JAMA. 2020 Feb 7;323:10619.

82 Zhu J, Zhong Z, Ji P, Li H, Li B, Pang J, et al. Clinicopathological characteristics of 8697 patients with COVID-19 in China: a metaanalysis. Fam Med Community Health. 2020; 8(2):e000406

83 Román GC, Spencer PS, Reis J, Buguet A, Faris MEA, Katrak SM, et al. The neurology of COVID-19 revisited: a proposal from the Environmental Neurology Specialty Group of the World Federation of Neurology to implement international neurological registries. J Neurol Sci. 2020 15;414:116884.

84 Feinstein JS, Buzza C, Hurlemann R, Follmer RL, Dahdaleh NS, Coryell WH, et al. Fear and panic in humans with bilateral amygdala damage. Nat Neurosci. 2013 Mar;16(3):270-2.

85 Zheng Z, Peng F, Xu B, Zhao J, Liu H, Peng J, et al. Risk factors of critical \& mortal COVID-19 cases: a systematic literature review and metaanalysis. J Infect. 2020 Apr 23;81(2):e1625.

86 Johnson MJ, Close L, Gillon SC, Molassiotis A, Lee PH, Farquhar MC, et al. Use of the modified Borg scale and numerical rating scale to measure chronic breathlessness: a pooled data analysis. Eur Respir J. 2016 Jun; 47(6):1861-4

87 Tobin MJ. Dyspnea. Pathophysiologic basis, clinical presentation, and management. Arch Intern Med. 1990 Aug;150(8):1604-13.

88 Kamal M, Abo Omirah M, Hussein A, Saeed $\mathrm{H}$. Assessment and characterisation of postCOVID-19 manifestations. Int J Clin Pract. 2020 Nov 3;75:e13746.

89 Carfi A, Bernabei R, Landi F; Gemelli Against COVID-19 Post-Acute Care Study Group. Persistent symptoms in patients after acute COVID-19. JAMA. 2020 Aug 11;324(6):6035.

90 Versace V, Sebastianelli L, Ferrazzoli D, Romanello R, Ortelli P, Saltuari L, et al. Intracortical GABAergic dysfunction in patients with fatigue and dysexecutive syndrome after COVID-19. Clin Neurophysiol. 2021 May; 132(5):1138-43.
91 Wostyn P. COVID-19 and chronic fatigue syndrome: is the worst yet to come? Med Hypotheses. 2021 Jan;146:110469.

92 Ortelli P, Ferrazzoli D, Sebastianelli L, Engl M, Romanello R, Nardone R, et al. Neuropsychological and neurophysiological correlates of fatigue in post-acute patients with neurological manifestations of COVID-19: insights into a challenging symptom. J Neurol Sci. 2021 Jan;420: 117271.

93 Clauw DJ, Häuser W, Cohen SP, Fitzcharles MA. Considering the potential for an increase in chronic pain after the COVID-19 pandemic. Pain. 2020 Jun 26; 161:16947.

94 Shiers S, Ray PR, Wangzhou A, Sankaranarayanan I, Tatsui CE, Rhines $\mathrm{LD}$, et al. ACE2 and SCARF expression in human dorsal root ganglion nociceptors: implications for SARS-CoV-2 virus neurological effects. Pain. 2020;161(11):2494-501.

95 Coen M, Kaiser C, Naimi R, Uginet M, Hentsch L, Serratrice J, et al. Beyond silent hypoxemia: does COVID-19 can blunt pain perception? Comment on The neuroinvasive potential of SARS CoV2 may play a role in the respiratory failure of COVID 19 patients. J Med Virol. 2021 Apr;93(4): 1915-6.

96 Moutal A, Martin LF, Boinon L, Gomez K, Ran D, Zhou Y, et al. SARS-CoV-2 spike protein co-opts VEGF-A/Neuropilin-1 receptor signaling to induce analgesia. Pain. 2020 Oct 1;162:24352.

97 Bausewein C, Farquhar M, Booth S, Gysels M, Higginson IJ. Measurement of breathlessness in advanced disease: a systematic review. Respir Med. 2007 Mar;101(3):399410.

98 Yorke J, Moosavi SH, Shuldham C, Jones PW Quantification of dyspnoea using descriptors: development and initial testing of the Dyspnoea-12. Thorax. 2010 Jan;65(1):21-6.

99 Tan JY, Yorke J, Harle A, Smith J, Blackhall F, Pilling M, et al. Assessment of breath lessness in lung cancer: psychometric properties of the Dyspnea-12 questionnaire. J Pain Symptom Manage. 2017 Feb; 53(2):208-15

100 Guyatt GH, Berman LB, Townsend M, Pug sley SO, Chambers LW. A measure of quality of life for clinical trials in chronic lung disease. Thorax. 1987 Oct;42(10):773-8.

101 Johnson MJ, Oxberry SG, Cleland JG, Clark AL. Measurement of breathlessness in clinical trials in patients with chronic heart failure: the need for a standardized approach: a systematic review. Eur J Heart Fail. 2010 Feb; 12(2):137-47.

102 Banzett RB, Moosavi SH. Measuring dyspnoea: new multidimensional instruments to match our 21st century understanding. Eur Respir J. 2017 Mar;49(3):1602473.

103 Campbell ML. Psychometric testing of a respiratory distress observation scale. J Palliat Med. 2008 Feb;11(1):44-50. 